\title{
IdeAs
}

Idées d'Amériques

$6 \mid 2015$

Migrer dans les Amériques

\section{La Inmigración de posguerra en la Argentina: identidad individual, identidad familiar y fuentes epistolares}

L'immigration d'après-guerre en Argentine: l'identité individuelle, l'identité de la famille et les sources épistolaires

Postwar immigration in Argentina: individual identity, family identity and epistolary sources

\section{María Liliana Da Orden}

\section{OpenEdition}

Journals

Édition électronique

URL : https://journals.openedition.org/ideas/1211

DOI : 10.4000/ideas. 1211

ISSN : $1950-5701$

Éditeur

Institut des Amériques

Référence électronique

María Liliana Da Orden, «La Inmigración de posquerra en la Argentina: identidad individual, identidad familiar y fuentes epistolares », IdeAs [En ligne], 6 | 2015, mis en ligne le 11 décembre 2015, consulté le 18 octobre 2022. URL : http://journals.openedition.org/ideas/1211 ; DOI : https://doi.org/10.4000/ ideas. 1211

Ce document a été généré automatiquement le 18 octobre 2022

\section{(c) $(1) \odot$}

Creative Commons - Attribution - Pas d'Utilisation Commerciale - Pas de Modification 4.0 International - CC BY-NC-ND 4.0

https://creativecommons.org/licenses/by-nc-nd/4.0/ 


\title{
La Inmigración de posguerra en la Argentina: identidad individual, identidad familiar y fuentes epistolares
}

\author{
L'immigration d'après-guerre en Argentine: l'identité individuelle, l'identité de \\ la famille et les sources épistolaires \\ Postwar immigration in Argentina: individual identity, family identity and \\ epistolary sources
}

María Liliana Da Orden

es desesperante pensar la distancia que nos

separa y que

la única esperanza que tenemos es que el cartero

desgraciado

se acuerde de nosotros para no terminar de enloquecer $[. . .]^{1}$.

\section{Introducción}

Durante el período de inmigración masiva, más de cuatro millones de europeos tuvieron a la Argentina como destino. Como en otros países, este flujo se debilitó en los años treinta del siglo pasado y tuvo una reactivación en los años que siguieron a la posguerra. Aunque con una magnitud mucho menor -cerca de novecientos mil inmigrantes-, también aquí los grupos mayoritarios estaban conformados por italianos y españoles. Este fenómeno ha dado lugar a una importante historiografía centrada en el cruce del siglo XIX al XX, un período que se ha caracterizado por la modernización de la sociedad argentina. Esta problemática ha sido abordada desde diversas perspectivas la historia social, la historia de la familia, la microhistoria- con una sofisticación 
metodológica que apeló a una gran variedad de fuentes (Devoto F., 2003). Entre otras, desde hace algunos años comenzaron a utilizarse los epistolarios privados, un testimonio cuyo empleo -y abundancia- posee una trayectoria en la historiografía norteamericana y de otros contextos que aquí todavía no ha alcanzado ${ }^{2}$. No obstante, la correspondencia se ha mostrado muy fructífera para estudiar las prácticas sociales desde la perspectiva de los sujetos: el funcionamiento de las cadenas migratorias ${ }^{3}$, los problemas derivados de la vida cotidiana en la nueva sociedad -obtención de trabajo, vivienda, etc. $O$ los intercambios con la tierra de origen. Menos consideradas han sido las cartas en su especificidad, esto es, como un género que hace factible abordar a la intimidad de los sujetos.

2 Sin embargo, hace ya más de sesenta años que Gino Germani (1962), el sociólogo italiano que signó la agenda de estos estudios en el país, manifestara su interés por esta cuestión. Al considerar el proceso de integración o, en sus términos, de asimilación/ fusión, ubicó en primer lugar la adaptación personal basada en «criterios subjetivos propios de cada individuo.» Aunque era consciente de lo poco que se sabía sobre el tema, apuntó dos aspectos: el de los costos en términos de sufrimiento, penurias y restricciones no sólo materiales que supuso la inmigración y la cuestión -muy vinculada al funcionalismo-, de la «desorganización familiar y personal» que habría provocado ese proceso. Con otros enfoques las investigaciones posteriores privilegiaron, en cambio, la dimensión social de la adaptación de los inmigrantes, de manera que si es mucho lo que se ha avanzado en el conocimiento de distintos colectivos, es poco lo que se adelantó en el estudio de los aspectos personales que implicó este proceso.

3 En tal sentido, las cartas y otros testimonios personales constituyen un instrumento privilegiado. Dependiendo de su frecuencia y del arco temporal que abarque, la correspondencia personal constituye en cierto modo la expresión de una conciencia de sí más o menos explicitada pero también, la manifestación de los intereses y preocupaciones que supuso la inmigración a la nueva sociedad. La dimensión personal a la que se refería Germani.

4 Ahora bien, como ha señalado la crítica literaria y también la historiografía en otros ámbitos, las cartas privadas constituyen un género que responde a ciertas reglas. Entre otras -tal vez la más importante para nuestro objetivo-, la de establecer por escrito una suerte de diálogo con el que se halla ausente pero también con el propio «autor», que además es el primer lector. Un proceso que, por cierto, no escapa a las características de la representación, por cuanto quien escribe se hace presente ante el otro, el destinatario, con los condicionamientos que impone la ausencia y la mediación de la escritura, que muestra pero no puede -y en ocasiones no quiere- hacerlo de manera transparente (Pagés-Rangel R., 1997). Por tanto, como toda representación, la imagen que ofrece la persona que escribe alude y elude al mismo tiempo. Claro que esto puede suponer un margen amplio dependiendo del objetivo más o menos instrumental que persiga la carta y también del dominio de la escritura por parte del «emisor», una competencia que no necesariamente se halla determinada por la educación sistemática. De hecho, es sabido que los inmigrantes analfabetos solían recurrir a mediadores, verdaderos «escribas», para satisfacer su necesidad de comunicación.

5 Sin entrar en mayores especificaciones sobre estos escritos personales -diferentes a las memorias, por su contemporaneidad con las situaciones a las que se refieren, pero distintos a su vez de los diarios íntimos (Franzina E., 1992)-, nuestro trabajo explora las 
formas de creación y recreación de la identidad individual y familiar -constitutivas de la subjetividad personal- buscando proponer algunas cuestiones que permitan avanzar en el estudio de la adaptación de los inmigrantes de posguerra en la Argentina. Utilizaremos para ello el epistolario del miembro de una familia de italianos procedentes del centro de Sicilia que se asentaron en la ciudad de Buenos Aires a fines de los años cuarenta. Como veremos, se trata de una colección de más de un centenar de cartas, la mayor parte de las cuales fueron escritas por una nativa en Valguarnera (provincia de Enna) que emigró de pequeña con su familia y un decenio más tarde retomó la emigración hacia otro destino dejando a una parte de sus parientes en la capital argentina. Como intentaremos demostrar, esta correspondencia sugiere que a pesar de las sucesivas migraciones, mucho después del ajuste inicial que supuso la inserción en sociedades bien distintas de la del origen, la familia «extendida» continuó teniendo un lugar central en la vida de estos inmigrantes, más allá del proceso de movilidad social al que aspiraron y en el que varios se vieron envueltos. Pero también y al mismo tiempo, las cartas se convirtieron en el instrumento de un proceso de adaptación donde la autonomía fue perdiendo parte de su poder. La continuidad de la correspondencia dio pues lugar a un doble juego donde a la autonomía individual se abrió paso frente a los intereses familiares sin que éstos a su vez dejaran de operar.

\section{La inmigración de posguerra a la Argentina}

6 Antes de adentrarnos en el análisis, nos detendremos a considerar algunos aspectos de la la corriente de la que formaron parte los inmigrantes que nos ocupan. Entre $1945 \mathrm{y}$ 1959 ingresaron por el puerto de Buenos Aires unos 900.000 inmigrantes, la mayoría de los cuales provenía de Italia -entre el 50\% y el $60 \%$ del total en los años de mayor afluencia- (Barbero M. I. y Cacopardo C., 1991). Como algunos estudios han señalado, la oleada de posguerra que se dirigió a la Argentina fue diferente de la que la precedió en el cruce de los siglos por su mayor acompañamiento familiar y, en menor medida, por la mejor calificación laboral que los caracterizó (Barbero M. I. y Cacopardo C., 1991; Devoto F., 2003). Mucho tenía que ver en ello las transformaciones producidas en el lugar de emisión y también en el país, ahora orientado a la industrialización. En cuanto a la procedencia, en la época masiva predominaron los italianos del norte hasta el cambio de centuria. Sólo en la década anterior a la Primera Guerra, las provincias del Mezzogiorno continental llevaron la delantera. Procedentes de espacios rurales retrasados económicamente, los que no retornaron, terminaron concentrándose en Buenos Aires y en otras ciudades.

7 Más tardía que la de otras regiones, la emigración siciliana se había dirigido hacia distintas zonas de la península y otros países europeos -Francia en primer lugar- y, por supuesto, hacia América. Aunque Estados Unidos ejercía el principal atractivo, también se asentaron en Brasil y Argentina ${ }^{4}$. A este país se orientaron los nativos del sudoeste y centro de la isla -Caltanissetta, por ejemplo, lindante con Enna-, frente a los de la zona palermitana, que casi exclusivamente emigraron a Norteamérica. Durante la segunda posguerra, en cambio, las limitaciones legales que allí se establecieron y las características de la economía escasamente industrializada de Argentina, que favorecía la inserción ocupacional, condujeron a un mayor arribo de sicilianos -laboralmente poco calificados-, al puerto de Buenos Aires, una tendencia que conocemos principalmente por los estudios del país de origen. 
8 Ahora bien, a pesar de su relevancia, no existen investigaciones sobre la procedencia de los peninsulares en el momento de su ingreso al puerto de Buenos Aires para este período. No obstante, una muestra de los oriundos de la provincia de Enna parece indicar que la presencia de familias estuvo aún más acentuada entre los nativos de la isla que en el conjunto de la migración, donde de por sí ya era significativa ${ }^{5}$. De hecho, la diferencia entre los sexos era bastante más baja que la del conjunto migratorio -el índice de masculinidad era de 137 varones cada cien mujeres frente a los 162 que presentaba el promedio-. De todos modos está claro que se estaba muy lejos del predominio de hombres solos que se dio entre los italianos de la gran oleada migratoria. Complementariamente, también era muy destacada la presencia de niños (casi una cuarta parte del total) y de individuos mayores de 60 años, otros tantos indicios del ingreso de familias cuyos miembros, además, pertenecían a varias generaciones. De manera que los núcleos conyugales completos solían emigrar al país junto con los padres y otros parientes, sea que viajaran en el mismo barco -las tres cuartas partes de los individuos de la muestra-, sea que lo hicieran en distintos momentos como fue el caso de la familia que consideramos.

9 También la calificación laboral se habría diferenciado si tenemos en cuenta que sólo una quinta parte de este colectivo fue registrado como agricultor en las listas de desembarco y más de la mitad figuró como obrero o jornalero. De manera que los oficios y profesiones, en su mayoría poco especializadas, tuvieron mayor relevancia que en la oleada anterior. En cualquier caso, se trataba de inmigrantes que, por su elevada concentración en la capital argentina y otras grandes ciudades, debieron aprender su oficio sobre la marcha, sin duda favorecidos por las oportunidades de empleo que ofrecía la época. De hecho, las investigaciones existentes muestran que la mayoría se ubicó en la industria o en la construcción.

10 Teniendo en cuenta estos grandes rasgos ¿cómo fue el recorrido de los protagonistas del epistolario que analizamos? Gaetano De Francisci, el primero del grupo familiar que llegó a Buenos Aires en abril de 1949, había embarcado en el Philipa con otros siete paisanos. Razones que seguramente se debieron a la accesibilidad del pasaje lo llevaron a viajar desde el puerto de Génova, tan lejos del lugar de origen. Desde Nápoles, en cambio, partió el resto de la familia tres meses más tarde. Así se reunieron con Gaetano, su esposa y un hermano menor con toda su familia. Se trataba de parejas que habían realizado matrimonios «enfrentados»: dos hermanos se habían casado con dos de las hermanas Vitale y estaban, pues, doblemente emparentados. El matrimonio más joven, Mariana y Carmelo, emigró con tres hijas pequeñas (la mayor con diez años), en tanto que Raquel y Gaetano no tenían hijos y ya superaban los 40 años. Ninguno fue registrado como agricultor o jornalero, como podría suponerse dada su procedencia. El mayor al parecer había sido obrero, en tanto que Carmelo, el menor, se declaró albañil. Como la mayoría, las mujeres figuraban como «caseras» al ingreso al país.

11 En esa época la ciudad a la que habían emigrado rondaba los tres millones de habitantes. Numerosos talleres y fábricas se habían incorporado al comercio y los servicios, particularmente en el Gran Buenos Aires, en cuyos municipios se concentraba más de un millón de individuos. Se trataba pues de un conglomerado urbano bien distinto de las ciudades y pueblos sicilianos. En efecto, Valguarnera, de donde procedían, contaba en la época unos 15.000 habitantes. Sin embargo, la Argentina peronista del pleno empleo y la industrialización ofrecía muchas oportunidades de trabajo, ahorro y progreso, a pesar de las crisis que pronto se avecinarían. Los jefes de 
ambas familias se asociaron en la construcción en su calidad de albañiles, oficio que tenía una importante gravitación entre los ennesi. A pesar de la creciente incorporación de la mujer al mercado de trabajo, las esposas, como la mayoría de las italianas, se mantuvieron en la casa aportando a los ingresos familiares a través de la costura y el ahorro que hacía posible la férrea administración del hogar.

El trabajo de los hombres incluía el trato frecuente, si no la asociación, con otros paisanos de la misma actividad, así como la relación con otros italianos del Mezzogiorno con quienes mantenían una estrecha proximidad, compartiendo incluso el vecindario. De hecho, en la periferia de Buenos Aires (Villa Maipú, en el límite con la capital) ambos matrimonios compartieron la misma vivienda y dos de las hijas, una vez casadas, criaron a sus hijos en ella o en otra contigua. De modo que a comienzos de los años sesenta, a más de una década de establecidos, los matrimonios del origen y dos hijas solteras (la menor nacida en el país) compartían el trabajo y la vida cotidiana con otros dos núcleos formados en el lugar, que habían incorporado a la familia a un inmigrante de Calabria y otro de Campobasso, además de un hijo pequeño. Cuatro familias nucleares que incluían a tres generaciones y catorce individuos, si se considera a la familia de uno de los yernos (los padres y una hermana soltera con quienes mantenían trato diario). Como también se ha observado en otras ciudades donde los italianos del sur se habían asentado (Favero B., 2013), a pesar (o en razón) de la migración, estos individuos habían re-creado una suerte de familia extensa en la nueva sociedad. Una configuración que no parece extraña si se considera el acompañamiento familiar con que arribó a Buenos Aires la mayoría de los ennesi y que daba cuenta del peso que tenía la parentela en el lugar de origen (Piselli F., 1981).

En esta instancia, con más de diez años de asentamiento en el país, fue forjado un nuevo proyecto: Carmelo y Mariana decidieron partir a Estados Unidos y probar suerte en Rochester. Con casi cincuenta años y una vida de duro trabajo retomaron el camino de la migración acompañados de Franca, la hija soltera de 20 años. Más allá de la crisis económica que afectaba al país, parece sorprendente la partida hacia otro destino migratorio antes que el retorno al lugar de partida que muchos emprendieron tanto desde el país como desde otros destinos migratorios ${ }^{6}$. Semejante desplazamiento, sin embargo, formaba parte del horizonte de posibilidades. En efecto, existía un movimiento hacia ese destino más vasto y antiguo: desde hacía varias décadas en la ciudad del norte se había formado una nutrida colectividad de sicilianos (Salamone F., 1994). Entre ellos, varias familias de paisanos de los De Francisi circulaban entre ambos polos, llevando y trayendo información.

14 Pero además, estos inmigrantes tenían su propia tradición al respecto. De hecho, Mariana, la esposa de Carmelo, había nacido en Baltimore, estado de Maryland, durante la estancia de sus padres y dos de sus hermanos en la primera década del siglo pasado7 ${ }^{7}$. De manera que esta experiencia formaba parte de la trayectoria familiar de las hermanas Vitale (ver el Anexo). Como en el caso de sus padres, también aquí la emigración de Mariana y parte de su familia parecía tener un carácter transitorio, si tenemos en cuenta que hijos, nietos y hermanos habían quedado en Buenos Aires en la propia vivienda. Sin embargo fue esta nueva migración la que dio lugar a un intercambio epistolar que se prolongó durante décadas.

15 Ahora bien, si la partida de Sicilia, desde el viaje hasta mucho después de los primeros años de inserción, no separó a los integrantes de estas familias, ¿en qué medida la nueva migración afectó las relaciones que implicaban el trato cotidiano? Dicho de otra 
manera, si a comienzos de los sesenta el parentesco mantenía unidos a estos inmigrantes en Buenos Aires, ¿hasta qué punto el nuevo desplazamiento permitió acrecentar el margen de maniobra individual y con ello el del propio núcleo conyugal? Una cuestión que ha ocupado a los estudiosos de las migraciones masivas y adquiere aquí un interés particular habida cuenta de las transformaciones socio-económicas y culturales operadas en la segunda mitad del siglo XX y la experiencia de sucesivas migraciones.

\section{Parentela y autonomía individual}

El nutrido epistolario recibido en Buenos Aires permite considerar estas cuestiones. Más allá de las pérdidas o la selección de que fue objeto, el corpus está integrado por más de 100 cartas y tarjetas escritas en su mayoría por las cuatro hijas del matrimonio que había vuelto a migrar. Desde 1963, con algunos vacíos, estos testimonios cubren más de cuatro décadas. Con distinta frecuencia según el emisor, se conserva un mínimo de dos cartas para cada año aunque este número llega a 17 en momentos clave como el reencuentro de las hermanas mayores en Sicilia. Aquí nos ocuparemos de la correspondencia de Franca, que mantuvo el intercambio más frecuente con su tía y madrina Raquel -un total de cincuenta envíos en las dos primeras décadas de su vida en el país del norte, de donde no retornó más que en viajes de visita ${ }^{8}$. Buena parte de la reconstrucción que ya realizamos surge de la lectura de las cartas conservadas en la capital argentina.

17 Por la índole de las fuentes utilizadas, la educación sistemática que había tenido la emisora y el período de importantes cambios personales y sociales que abarcan los escritos -la creciente «modernización» e individualismo de los sesenta y setenta en las grandes ciudades-, cabría esperar que la autonomía individual fuera más visible en estos testimonios que en otro tipo de evidencias. Sin embargo, en las cartas de Franca predomina un detalle de la vida familiar que no sólo atiende al propio núcleo -a tres años de instalada en Rochester había contraído matrimonio-, sino también al de los padres, hermanas y padrinos. Es cierto que las destinatarias de sus cartas, la madrina y su hermana también llamada Raquel, favorecían estas referencias, aunque el tiempo invertido en la escritura de extensas y numerosas cartas constituye un indicio del papel que desempeñaba el conjunto familiar.

Desde el punto de vista migratorio, podría suponerse que la experiencia de Franca en Argentina estaba dada por el universo familiar y parental, el lenguaje siciliano hablado en el hogar, las cartas y referencias a los parientes de «Italia» antes que por el extrañamiento que podría afectar a los que partieron de Sicilia en plena juventud o adultez. De manera que, ayudada por los compañeros de escuela y la vida en el barrio, su niñez no padeció el distanciamiento del lugar natal. La re-emigración habría reproducido así, con otro bagaje, la vivencia de los padres cuando se trasladaron a Buenos Aires. Es posible entonces, que el relato de sus cartas diera cuenta también de las experiencias y sentimientos de aquellos otros que, como los padres, sufrieran el primer «desarraigo.»

19 A comienzos de los años sesenta unos 320.000 habitantes residían en la ciudad de Rochester, que por ese entonces ya daba ciertos signos de crisis a pesar de su industrialización. Varios grupos étnicos se habían consolidado en el lugar como consecuencia de las diversas oleadas migratorias. Entre otros, un importante núcleo de 
sicilianos procedentes del centro de la isla. No obstante, además de la crudeza del clima, el idioma y el tipo de trabajo, las diferencias étnicas -mucho más marcadas que en Buenos Aires- imponían distancias tal vez más significativas que las espaciales entre las dos ciudades. Ciertamente la inserción de los italianos fue bien distinta en ambos países (Baily S., 2004). De este modo, los primeros tiempos en Rochester se centraron casi exclusivamente en una vida de extremo trabajo, con duros inviernos, donde a los ingresos del padre se sumaban los salarios de la esposa y la hija que aquí sí habían ingresado al mercado laboral -primero con «la aguja», después en una fábrica. Más allá de los cambios, como en la capital argentina, una red de parientes y paisanos -en las cartas se mencionan nueve familias cuyos lazos procedían de Sicilia y también de Buenos Aires-, seguramente ayudaron a contenerlos. Ello suponía desde la ayuda para conseguir trabajo hasta el uso del tiempo libre -visitas, casamientos y otras celebraciones. También se da cuenta de la vida asociativa: la sociedad a la que diariamente concurría el padre a pesar del disgusto de la madre, seguramente aquejada por la soledad a que ahora se enfrentaba sin la hermana y las hijas. Con el tiempo la vida pareció volver a su cauce a medida que la familia se fue reunificando. A pesar del nuevo contexto, las relaciones no parecieron haberse modificado en la ciudad norteamericana: las hijas solteras, estudiando o trabajando, residieron en la casa, contrajeron matrimonio dentro del mismo círculo de relaciones y se mantuvieron en el hogar o en sus cercanías, de manera que el trato cotidiano no se interrumpió. De hecho, al reunirse con ellos la hija mayor con su esposo y un hijo, la casa del núcleo de origen fue el lugar donde permanecieron varios años. Como en la lejana Villa Maipú, durante más de una década tanto la vieja como las nuevas familias y sus hijos vivieron en Rochester en un estrecho ámbito relacional y también espacial, donde también se insertaban otros parientes y paisanos. Posiblemente por las necesidades generadas por la emigración, tanto en la ciudad argentina como en el destino del norte se habría recreado una forma del vicinato que tanta importancia tuviera en la vida familiar y laboral del sur peninsular (Piseli F., 1981).

Las primeras cartas mantienen fresco el relato cotidiano de este tipo de vida -«la rutina», la salud, las referencias a parientes y paisanos, las preguntas por los que vivían en Buenos Aires -, pero también de la melancolía, el extrañamiento y sobre todo la preocupación cuando las cartas no llegaban. En el mes de enero de 1964, Franca escribía, «Hace desde Navidad que no recibimos noticias vuestras, mamá y todos estamos desesperados pensando que algo malo pudo haber sucedido es terrible esperar día a día alguna carta ${ }^{9} . »$ La importancia dada al intercambio epistolar, así como la información pormenorizada que tenía como destinataria a la «madrina», eje de las relaciones familiares que permanecieron en Buenos Aires, confirman el lugar asignado a la familia de origen que también contenía a esta madre simbólica. Ese intercambio, las fotografías y las tarjetas enviadas en cada aniversario, no parecían suficientes a juzgar por las expresiones que encabezaban las cartas -«madrinísima»; «Querida e irremplazable», «tesoro»-, y se reiteraban en el texto:

[...] Nosotros no somos una familia compuesta solamente por madre padre y los hijos sino que son ellos y infaltablemente tambien madrina y padrino, yo se que en este momento vos madrina constituis el sostén de todos material y sobre todo espiritual, mamá siempre te tiene presente en todo lo que hace y dice a vos padrino también ${ }^{10}$.

21 Como indica este fragmento, las expresiones de afecto tenían por cierto una base material: el dinero facilitado para la emigración de Franca y los miembros que le 
siguieron, el mantenimiento de la casa compartida, el cuidado de la hermana adolescente. Cierto es que las cuentas pendientes debían ser saldadas, pero también lo es que este intercambio tenía dos direcciones y se reproducía en el tiempo -las pequeñas inversiones realizadas en Rochester en nombre de los padrinos, por ejemplo. ${ }^{11}$ Sin embargo, tal como se alude en el mismo texto este lazo familiar no sólo conllevaba un soporte externo: a la madrina se pedía consejo, se daban explicaciones - «no se crean que nosotros estamos gozando de la America y que descartamos a todos ustedes»-, se admitían reproches - «juzgame como quieras pero eso es lo que siento ${ }^{12}$.» En buena medida esto se basaba en la «ruptura» que la nueva emigración había impuesto a esta familia extendida. En efecto, la partida de la ahijada con los padres, a la que siguieron dos de las hermanas y el sobrino-nieto, si tuvo como finalidad el progreso que había motivado la partida de Sicilia, también generó incertidumbres y tiranteces. Para la madrina y su esposo, que habían promovido la primera migración y tan ligados se mantuvieron con aquéllos, el nuevo proyecto tensaba el anterior: si continuaba con las aspiraciones de una vida más acomodada también introducía un elemento inquietante en las relaciones cotidianas ${ }^{13}$. De ahí la justificación, el reconocimiento, el refuerzo del afecto que atravesaba el epistolario: «sos la piedra fundamental en la estructura espiritual y moral de nuestra familia.»

Pero además las cartas tenían otro valor que parecía justificarlas. Aunque no contamos con las respuestas de la madrina, las cartas de Franca permiten entreverlo. En los escritos mecanografiados -la manifestación de un logro no sólo material-, aquélla buscaba evidenciar una competencia que daba cuenta de otras aspiraciones. En efecto, los elogios de la ahijada, los pedidos de disculpas por la redacción, dejaban ver hasta qué punto Raquel buscaba construir una imagen de sí que era aceptada y a la vez reforzada por Franca: «no se si me llegas a entender por supuesto no se escribir las hermosas y emotivas cartas tuyas»; o bien, «tu redacción es magnifica y superlativa y me deja muy admirada tu descripción de personas y sentimientos que demuestran una mente alerta y fresca. Pero conmigo [agregaba] si te es más fácil expresarte de una manera más sencilla lo acepto y aprecio lo mismo $^{14}$.» Es posible ver así el artificio que implicaba la correspondencia. Invención y construcción que la destinataria en Buenos Aires ratificaba a través de la custodia celosa de las cartas (clasificadas por año) que permitió su conservación ${ }^{15}$. Con fotografías y tarjetas que completaban tales envíos, Franca por su parte también manifestaba esta necesidad de inventar (en el sentido de re-crear) el afecto, el «palpitante cariño», cada cumpleaños, cada «día de la madre», cada Navidad. De manera que la escritura de las cartas podría concebirse como la construcción de una suerte de monumento de y por parte de Raquel, y un tributo que Franca ofrecía a la relación que el trato cotidiano había forjado y, sin embargo, la distancia y el tiempo ya habían desvanecido.

24 La tensión que esta realidad construida con cartas buscaría aliviar, en buena medida alude a algo más profundo que la trasciende: el papel que tenía en la familia esta madrina-madre (como varias veces la mencionan los escritos) o más precisamente la imagen que suponía y que también le era adjudicada. La maternidad simbólica que compartía con la madre de esta ahijada, reforzada por la doble condición de hermana y cuñada, supone explorar una figura central en las sociedades mediterráneas, si es posible esta generalización. Su figura ofrece una vía privilegiada para considerar la índole de las relaciones familiares. 
la guardiana de la armonía del hogar. Como tal era la mediadora nata en los inevitables conflictos que acarreaba la estrecha convivencia. «Los ánimos de la casa de mamá son mezclados, la relaciones entre Rosita y Rita a veces son como carne y uña y otras veces no se pueden ver y se reprochan cosas una a la otra, mamá pobre siempre está en el medio y recibe de las dos.» También, «Desde que volvió mamá parece como milagro todo retomó un curso ordenado, papá al que temía tanto por lo que podría hacer, se derritió como manteca». Un desempeño que si generaba cercanía e incluso permitía el reproche ${ }^{20}$, también establecía duras exigencias,

Por momentos la soledad y la tristeza me abaten pero luego me hago coraje por mi misma tengo muchas oportunidades de tener amigas y poder salir pero primero no les tengo confianza y segundo que si yo salgo mamá queda sola adentro porque papá se va a la sociedad ${ }^{21}$.

El seguimiento de un proyecto familiar y con ello la postergación - de la madre ante el esposo y de la hija frente a la madre-, condicionaban el desenvolvimiento individual. De manera que el lugar que seguían manteniendo las relaciones familiares tenía un reverso que todavía era perceptible cuando la hija había formado su propio núcleo conyugal. Así, la madre continúa tomando decisiones, pidiendo atención, victimizándose - « $\mathrm{O} \mathrm{h}$ quien mas sacrificada de ella! ${ }^{22}$ », resumía otra de las hijas.

El lugar que las cartas atribuyen a la madre y, por el destino que tenían, también a la madrina, tenía pues la fortaleza y ductilidad que hacía posible la combinación de poder y cercanía. Sin embargo, el epistolario también da cuenta que el desempeño de este rol podía tener otras imágenes. Si el reverso de este vínculo está dado por el mantenido con la suegra, los rasgos que la representan ponen de manifiesto las duras aristas que 
también implicaba la relación con los hijos. En efecto, como esposa conciliadora Franca da cuenta de los extremos a que podía llegar el ejercicio de la autoridad materna:

He llegado a sostener discusiones con él por este motivo y se niega a toda fuerza y dice 'yo se lo que escucharon estos oídos, me siento demasiado herido' primero fue el hijo perfecto cuando estaba a su disposición cuando ya quise con mi derecho levantar vuelo me volví villaco y caroña ${ }^{23}$.

El control, los celos entre familias e incluso la ira con su carga de violencia, eran capaces de desencadenar conflictos que, por las características de los lazos, no sólo involucraban a los hijos. Como en tantas otras situaciones, aún las referidas al ámbito público, el conflicto suele iluminar realidades más profundas que en situaciones normales es difícil identificar. Así, cuando estalla el enfrentamiento, la intervención de madres (consuegras), hijos, tíos y hasta paisanos parece arrastrar a los individuos sin diferenciarlos de la totalidad familiar en que se veían envueltos ${ }^{24}$.

Sin embargo, la índole de estas relaciones no permaneció inalterable. Con diversas estrategias que las cartas ponen en evidencia y seguramente contribuyeron a desarrollar, la generación siguiente habría forjado un nuevo tipo de vínculos donde el poder que ejercía la madre y a través de ella la partentela ya no tenía esa fuerza de atracción. Claro que este proceso no estuvo ajeno a la confrontación. La mudanza del nuevo núcleo a California, si contó con una red de parientes que la contuvo, también se enmarcó en una tirantez que había puesto en juego la armonía familiar, tantas veces mencionada. Aunque continuaba dentro de casa, ¿en qué medida el desplazamiento de Franca y su familia no evidenció o incluso habilitó el despliegue de una mayor autonomía? Así, el hogar y la crianza de los hijos continuaron atrayendo su energía e interés aunque la maternidad y la familia ya no se consideraban excluyentes. De acuerdo con «sistema americano de ser lo mas posible autosuficiente», señala,

Ya he terminado mi curso y estoy orgullosa [...] porque fue algo que empecé y termine hasta el fin, me ha hecho mucho bien emocional e intelectualmente. En enero empezare otro corto curso para ser asistente clínica [...], eso me dara mejor posibilidad para futuros empleos el dia que me decida tomar un empleo. La verdad es que me da miedo tomarme la responsabilidad de trabajar afuera, cuando la familia todavía me necesita, con Ernesto que no está tan entusiasmado y tener que perder mi libertad ${ }^{25}$.

Con ambigüedades y temores, el lugar "emocional e intelectualmente» asignado al desarrollo personal a medida que crecían los hijos, da cuenta de un individualismo que no había alcanzado a la generación de la madre. La afirmación de un individualismo que se confirma e incluso se acentúa en otros miembros de la familia. Así, las hermanas que también habían emigrado parecieron ir más lejos: con divorcios y exitosas carreras laborales incorporaron elementos subversivos frente al orden materno en un proceso, que sin embargo, tampoco fue lineal. Habría sido la hija que permaneció Buenos Aires junto a la madrina, al cuidado de una familia numerosa, la que pareció continuar con el papel de la generación anterior. ¿Influencia de sociedades y culturas tan distintas en las que finalmente estas mujeres se insertaron? Difícil encontrar una respuesta unívoca. Las cartas a la madrina de esta siciliana (¿argentina?) varias veces inmigrante evidencian la complejidad, a veces inasible, de los derroteros personales, en ningún caso solamente individuales. 


\section{A modo de cierre}

La correspondencia personal que aquí consideramos ofrece una particular vía de acceso para indagar la adaptación personal de los inmigrantes de posguerra en las sociedades receptoras, una cuestión mucho menos abordada que la dimensión social del fenómeno. Dando cuenta de necesidades que iban más allá del intercambio de información o de ayuda material, las cartas permiten entrever las formas de recreación de los lazos familiares y con ello de la propia identidad frente a los cambios que imponían los grandes desplazamientos. Más allá de la incidencia de la madrina, a quien iban dirigidos los escritos, ofrecen una visión de la familia que abarcaba a los miembros de tres generaciones. Esto suponía una estrecha relación de los individuos con sus padres y parientes que se hallaba vertebrada en torno a la figura materna. Configuración que si se había modificado frente a la de las familias del punto de partida en la península, no era por cierto demasiado diferente. Antes bien, la fortaleza de una red de relaciones donde la parentela continuaba operando en los individuos más jóvenes y sus propias familias, resulta por demás llamativa. Y ello era así independientemente de las sucesivas migraciones - del centro de la isla a Buenos Aires, desde esa capital a Rochester- y la inserción en sociedades urbanas más o menos industrializadas de los años setenta y ochenta del siglo pasado.

Es cierto que estos sicilianos formaron parte de la corriente de posguerra que llegó a la Argentina, una oleada que a diferencia de la masiva estuvo compuesta por buen número de grupos familiares ampliados, a veces completos. Sin embargo, el trabajo en Buenos Aires, la adquisición de la casa, la vida en el barrio o la escuela, no parecen haber modificado ese entramado. La familia continuaba signando la vida de los individuos, ejerciendo una fuerza de atracción sobre los nuevos núcleos y sus hijos. Un universo parental y étnico -aunque no cerrado-, que en las ciudades argentinas también caracterizó a otros grupos del Mezzogiorno asentados en la misma época. Una característica que, sin embargo, no definió a otros colectivos. El caso de los gallegos, mayoritarios entre los españoles - la otra corriente dominante-, desde el momento del arribo ofrece el ejemplo de un comportamiento mucho menos anclado en la parentela (Da Orden M. L., 2010; De Cristóforis N., 2008).

En cualquier caso, es factible sostener, como en otros contextos, que la migración de posguerra estuvo lejos de debilitar o desorganizar a la familia. Tales vínculos fueron capaces de adaptarse y extender su influencia más allá de las distancias y las transformaciones que conllevó la creciente modernización. Sin embargo, entre aquellos que habían emigrado de pequeños este cambio también favoreció el despliegue de la autonomía individual. Para que se diera ese doble movimiento fue necesario «inventar» la parentela, recreándola y haciendo concesiones. Los escritos brindan testimonio de esta negociación. Pero también, su existencia como objetos deseados y esperados que podían acumularse y conservarse. En su caso, Raquel como madre simbólica, había podido construir un monumento que preservaba y remitía a la unión familiar. La correspondencia de Franca, por su parte, fue la suerte de tributo que permitió reconocer y a su vez desplazar el poder que ejercían los intereses familiares sobre los individuos. En este sentido, entonces, las cartas pueden considerarse en un doble papel. Claramente son para el historiador un género particular en el arco posible de fuentes. Pero además del contenido, el continente. La materialidad de las cartas en sí misma dio 
pábulo a otras prácticas sociales que también ayudaron a construir identidades individuales y familiares de las que aquí sólo damos un ejemplo.

\section{BIBLIOGRAPHIE}

Cacopardo, Cristina y José Luis Moreno, «La emigración italiana meridional a la Argentina: Calabreses y sicilianos (1880-1930)» en Boletín del Instituto de Historia Argentina y Americana Dr. E.

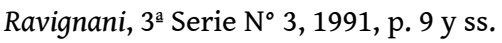

Barbero, María Inés y Cristina Cacopardo, «La emigración europea en la Argentina en la segunda posguerra: viejos mitos y nuevas condiciones», Estudios Migratorios Latinoamericanos, diciembre, 1991, № 19, p. 291-321.

Baily, Samuel, Immigrants in the Lands of Promise: Italians in Buenos Aires and New York City, 1870-1914, Ithaca, Cornell University Press, 2004.

Castiello, Nicolino, «Emigrazione dal sud in Argentina» Mélanges de l'Ecole française de Rome. Italie et Méditerranée, $\mathrm{N}^{\circ} 112,2000$, p. 401-414.

Cinel, Dino (1991) The National Integration of Italian Return Migration, 1870-1929, Cambridge University Press.

Devoto, Fernando, Historia de la inmigración en la Argentina, Buenos Aires, Sudamericana, 2003.

Devoto, Fernando, Historia de los italianos en Argentina, Buenos Aires, Biblos, 2006.

Da Orden, María Liliana, Una familia y un océano de por medio. La emigración gallega a la Argentina: Una historia a través de la memoria epistolar, Barcelona, Anthropos, 2010.

De Cristóforis, Nadia «El último ciclo de la inmigración gallega en la Argentina: una aproximación a sus rasgos principales» en N. De Cristóforis y A. Fernández (eds.) Las migraciones españolas a la Argentina. Variaciones regionales (siglos XIX y XX), Buenos Aires, Biblos, 2008, p. 77-105.

Favero, Luigi y Graziano Tasselo, «Cent'Anni Di emigrazione italiana (1876-1916)» en F. Balleta et alt (a cura di) Un secolo di emigrazione italiana. 1876-1976, Roma, Centro Studi Emigrazione, 1978, p. 9-64.

Favero, Bettina, La última inmigración. Italianos en Mar del Plata (1945-1960), Buenos Aires, Imago Mundi, 2013.

Franzina, Emilio, «Autobiografías y diarios de la emigración. Experiencia y memoria en los escritos autobiográficos de emigrantes e inmigrados en América entre los siglos XIX y XX» en Historia Social, Valencia, № 14, 1992, p. 121-142.

Gerber, David A., Authors of Their Lives. The Personal Correspondence of British Immigrants to North America in the Nineteenth Century, New York University Press, New York/ London, 2007.

Germani, Gino, Política y sociedad en una época de transición. De la sociedad tradicional a la sociedad de masas, Buenos Aires, Paidós, 1962.

Pagés-Rangel, Roxana, Del dominio público: itinerarios de la carta privada, Ámsterdam/ Atlanta, Editions Rodopi, 1997. 
Piselli, Fortunata, Parentela ed emigrazione. Mutamenti e continuità in una comunità calabrese, Turin, Einaudi, 1981.

Salamone, Frank, «Power and dominance in Sicilian households in Rochester» en Studi Emigrazione, Vol. 31, N 113, 1994, p. 64-90.

Sanfilippo, Mateo, «L'emigrazione siciliana», Archivio storico dell'emigrazione Italiana, 3, 1, 2007, p. 79-95.

\section{ANNEXES}

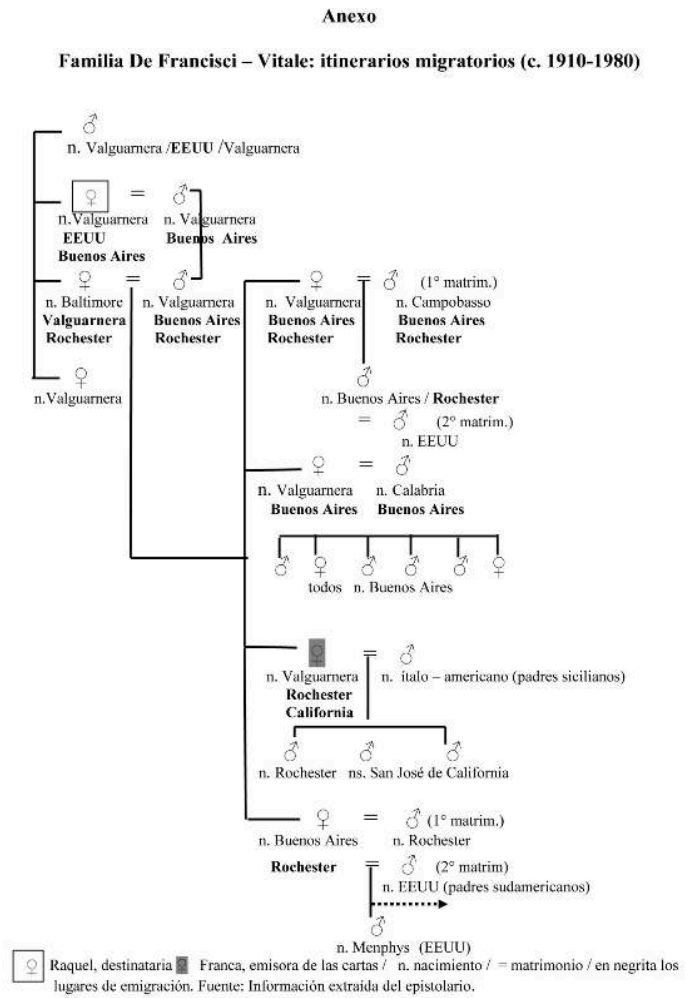

\section{NOTES}

1. Raquel a «queridísima madrina y todos,» datada en Buenos Aires con destino a Valguarnera, Sicilia, 9 de agosto de 1967.

2. Desde el clásico estudio de William Thomas y Florian Znanieckiky, los estudios migratorios apoyados en el análisis de la correspondencia personal han tenido un gran desarrollo en Estados Unidos. Una muestra de ello puede verse en la bibliografía que retoma David Gerber (2007) en su obra.

3. El concepto de cadena migratoria (chain migration) es muy utilizado en la historiografía argentina de las migraciones. En los años ochenta del siglo pasado fue introducido por Samuel Baily quien lo tomó de los estudios de John y Leatrice Mac Donnald sobre la inmigración italiana en Australia.

4. Del conjunto de la emigración meridional, los calabreses fueron los que en mayor medida tomaron el destino rioplatense, en tanto que los sicilianos prefirieron los Estados Unidos 
(Cacopardo C. y Moreno, J. L., 1994; Devoto F., 2008). Sobre la emigración siciliana de posguerra entre otros: Castiello N., 2000; Favero L. y Tasello G., 1978; Sanfilippo M., 2007.

5. Las consideraciones que realizamos se basan en una muestra de 902 individuos nativos de distintos municipios de la provincia de Enna -de donde procedían los miembros de las familias que consideramos- que desembarcaron en el puerto de Buenos Aires entre 1948 y 1956. Base de datos del Centro de Estudios Migratorios Americanos [en línea] http://www.cemla.com/ busqueda.php [consulta: enero de 2012]. Para la caracterización del conjunto de la inmigración de posguerra consideramos el estudio de María Inés Barbero y Cristina Cacopardo (1991), que aún permanece aislado.

6. El elevado retorno de italianos preocupaba a las autoridades migratorias argentinas de los años cincuenta. Para el caso norteamericano, la importancia de este movimiento entre los peninsulares de la oleada masiva ha sido estudiada por Cinel D., 1991.

7. Los registros de inmigración dan cuenta del ingreso de los Vitale por el puerto de Nueva York en 1906. [Fuente en línea:] http://www.ellisisland.org [consulta: enero de 2012.]

8. La colección está compuesta por 143 cartas que las cuatro hermanas enviaron a su madrina Raquel desde distintos lugares de residencia. De Franca, que emigró con los padres, se conservan 60 cartas y varias tarjetas entre 1964 y principios de este siglo. Aquí tendremos en cuenta las que abarcan los primeros veinte años, desde los tiempos de asentamiento inicial, la paulatina llegada de las hermanas -1965 y 1967 - y formación de las respectivas familias. El corpus ha sido transcripto y digitalizado por el Centro de Documentación Epistolar de Buenos Aires [en línea:] http://www.cartas.org.ar [consultado en agosto de 2011.]

9. Franca a "Querida e inolvidable madrina», Rochester, 18-1-1964. En adelante, siempre que no aclaremos, la indicación del lugar y las fechas corresponden a las cartas dirigidas por Franca a su madrina.

10. La ortografía y la gramática es respetada en todos los casos. Rochester, junio de 1963, también 18/1/64 y enero/1973.

11. Rochester, enero y marzo de 1968.

12. Rochester, 1/6/1963; San José [California] enero/1976.

13. Entrevista a Mateo N. (sobrino de Franca), Buenos Aires, setiembre de 2011.

14. Rochester, $1 / 6 / 1964$.

15. Uno de los descendientes de esta familia recuerda a la madrina leyendo a su madre las cartas que escribía y el interés que tenía por evidenciar su competencia literaria. Entrevista a Mateo N. ya citada.

16. Rochester, 2/2/1964, 26/5/1967, 20/8/1970.

17. Así, por ejemplo «Mi embarazo sigue adelante gracias a Dios, y estoy tanto o más emocionada que el primero, y cuando siento movimiento, experimento la plenitud de mis instintos de mujer y madre, todavía faltan 3 meses, y estoy muy ansiosa de saber lo que es, mientras tanto mi pensamiento todos los dias es preguntarme por el cuarto [...].» Rochester, 20/8/1970. También 18/8/1966; 13/9/1967; 11/12/1969.

18. Otra hermana, refiriéndose a la madrina lamenta «no haya podido (o sabido) como tu integrar submisión y poder al mismo tiempo.» Rosa a madrina, enero/ 1991.

19. «[...] mamá como tu tambien está preocupada respecto a ella pensando la edad tan delicada y difícil que esta atravesando y no ve la hora de estarle cerca [...] P.D. Mamá quisiera recibir una carta escrita personalmente por Rita.» También, una vez en Rochester, «la Rita siempre sigue con su carácter independiente y muy poco se cura de la autoridad de papá o mamá, finalmente convenció a papá de comprarle un coche, [...] esperemos esto no traiga aparejados problemas en organización de las salidas [...].» Rochester, 21/2/ 1964 (resaltado nuestro) y 29/3/1968 respectivamente.

20. Rochester, $29 / 3$ y 8/11/1968 respectivamente. También Franca «a mamá», Rochester, 26/5/1967 y «a madrina», mayo de 1967. 
21. Rochester, $1 / 2 / 1964$.

22. Febrero 1979; 12/11/1983 y Rosa a madrina, Rochester, 18/4/1974, respectivamente.

23. Rochester, $6 / 5 / 1965$. Nótese el desplazamiento que puede suponer el cambio de pronombres: «fue» (el), «quise» (yo).

24. El siguiente fragmento da cuenta de tales situaciones: «En el aeropuerto encuentro a Lydia [cuñada] que me comunica que la madre [suegra] habia llamado y habia ido allá con los chicos, a esto me puse contentisima, pero paso seguido me di cuenta que la madre la habia convencido sobre algunos sucesos [...] y además me enfrentó diciendome porque mamá no para de hablar de esa horrible manera acerca de su madre, yo quedé estupefacta [...] Nos vinimos a casa a descansar y encuentro una carta de Leonora Manganaro [suegra] en respuesta a mi tarjeta enviada con la mejor intención por la paz y armonía de todos y me encuentro con un compendio de 2 carillas de odio y veneno concentrado dirigidos a mamá y Ernesto [esposo, hijo de aquélla], esto rebasó mi medida de capacidad y mi estado de ánimo era un caos, [...] mamá sabiendo esto llama a John y vienen todos acá [...] me preguntó que ahora que Lidia habia hecho la paz cuando ibamos a ir nosotros, y ahí exploté y ya te imaginás la escena que siguió [...] Ahora el epilogo mamá no me llama y la voy a tener que llamar yo.» Una situación que varios años más tarde aún no había concluido y enfrentaba a Montesantos y Manganaros (familias del esposo). Rochester, 25/1/1968 y San José [California], 1/10/1975, respectivamente. También Rochester, 29/3/1968 y 17/6/1969. 25. Franca a «queridos todos,» Navidad 1978.

\section{RÉSUMÉS}

L'article explore les moyens de création et de recréation de l'identité individuelle et familiale en proposant de s'interroger sur l'adaptation des immigrants d'après-guerre en Argentine. Pour cela on utilise la correspondance d'un membre d'une famille de Siciliens qui se sont installés à Buenos Aires à la fin des années quarante. Il s'agit d'une collection de plus d'une centaine de lettres, dont la plupart ont été écrites par une femme native de Valguarnera (province d'Enna) qui a émigré enfant, avec sa famille et qui, dans les années soixante, est repartie aux États-Unis en laissant certains de ses proches dans la capitale argentine. Dans le contexte des flux migratoires d'aprèsguerre vers l'Argentine, on examinera les caractéristiques que cette famille a en commun avec les Siciliens à leur entrée dans le pays. Dans la deuxième partie, centrée sur les lettres, on fait l'hypothèse que, malgré les migrations successives et le processus de mobilité sociale qu'elle connaît, la famille «élargie» a toujours une place centrale dans la vie de ces immigrants. Mais parallèlement, les lettres deviennent l'instrument d'un processus d'adaptation au cours duquel la parentèle perd une partie de son pouvoir. Ainsi, la continuité de la correspondance a donné lieu à un double jeu où l'autonomie individuelle se fraye un chemin face aux intérêts familiaux sans que ceux-ci cessent d'opérer.

El artículo explora las formas de creación y recreación de la identidad individual y familiar buscando proponer algunas cuestiones que permitan avanzar en el estudio de la adaptación de los inmigrantes de posguerra en la Argentina. Se utiliza para ello el epistolario del miembro de una familia italiana procedente de Sicilia que se asentó en la ciudad de Buenos Aires a fines de los años cuarenta. Se trata de una colección de más de un centenar de cartas, la mayor parte de las cuales fueron escritas por una nativa en Valguarnera (provincia de Enna) que emigró de niña con su familia y en los años sesenta retomó la emigración hacia Estados Unidos dejando a una parte 
de sus parientes en la capital argentina. En el marco de la corriente migratoria de posguerra que llegó a la Argentina, en primer lugar se consideran las características de la oleada de sicilianos a su ingreso al país y los rasgos que esta familia compartía con aquélla. En la segunda parte, centrada en la correspondencia, se sugiere que a pesar de las sucesivas migraciones y del proceso de movilidad social que experimentaron, la familia «extendida» continuó teniendo un lugar central en la vida de estos inmigrantes. Pero también y al mismo tiempo, las cartas se convirtieron en el instrumento de un proceso de adaptación donde la parentela fue perdiendo parte de su poder. Así, la continuidad de la correspondencia dio lugar a un doble juego donde la autonomía individual se abrió paso frente a los intereses familiares sin que éstos a su vez dejaran de operar.

The article explores the ways of creation and recreation of individual and family identity with the aim of proposing some directions that advance the study of adaptation of postwar immigrants in Argentina. The main source is the correspondence of a member of an Italian family from Sicily who settled in Buenos Aires in the late forties. It is a collection of more than a hundred letters, most of which were written by a native of Valguarnera (province of Enna) who emigrated as a child with his family and in the sixties left for the United States, leaving some of his relatives in the Argentinian capital. In the first part we consider the characteristics this family shared with the wave of Sicilians entering the country, in the context of the postwar migration flow to Argentina. In the second part, focusing on correspondence, I suggest that despite the successive migrations and the process of social mobility experienced, the "extended" family continued to have a central place in the lives of these immigrants. But at the same time, the letters became the instrument of a process of adaptation where the kin was losing some of its power. Thus, the continuity of the correspondence resulted in a double play where individual autonomy stepped ahead of family interests without entirely displacing them.

\section{INDEX}

Mots-clés : Immigration d'après-guerre, Argentine, sources épistolaires, famille élargie, identités, Siciliens

Palabras claves : Inmigración de posguerra, Argentina, fuentes epistolares, familia extendida, identidades, sicilianos

Keywords : Postwar migration, Argentine, epistolary sources, extended family, identities, Sicilians

\section{AUTEUR}

\section{MARÍA LILIANA DA ORDEN}

María Liliana Da Orden es profesora titular en el área de Historia Argentina e Investigadora del Centro de Estudios Históricos, Facultad de Humanidades, Universidad Nacional de Mar del Plata, Argentina. mldaor9atgmail.com 